\title{
Naftopidil for the treatment of urinary symptoms in patients with benign prostatic hyperplasia
}

This article was published in the following Dove Press journal:

Therapeutics and Clinical Risk Management

22 June 2011

Number of times this article has been viewed

\section{Naoya Masumori}

Department of Urology, Sapporo Medical University School of Medicine, Sapporo, Japan
Correspondence: Naoya Masumori Department of Urology, Sapporo Medical University School of Medicine, Sapporo 060-8543, Japan

Tel +8I I I 6II 2 I I I (ext 3472)

Fax+8I I| 6122709

Email masumori@sapmed.ac.jp

\begin{abstract}
Naftopidil, approved only in Japan, is an $\alpha 1$-adrenergic receptor antagonist ( $\alpha 1$-blocker) used to treat lower urinary tract symptoms (LUTS) suggestive of benign prostatic hyperplasia (BPH). Different from tamsulosin hydrochloride and silodosin, in that it has higher and extremely higher affinity respectively, for the $\alpha 1 \mathrm{~A}$-adrenergic receptor subtype than for the $\alpha 1 \mathrm{D}$ type, naftopidil has distinct characteristics because it has a three times greater affinity for the $\alpha 1 \mathrm{D}$-adrenergic receptor subtype than for the $\alpha 1 \mathrm{~A}$ subtype. Although well-designed large-scale randomized controlled studies are lacking and the optimal dosage of naftopidil is not always completely determined, previous reports from Japan have shown that naftopidil has superior efficacy to a placebo and comparable efficacy to other $\alpha 1$-blockers such as tamsulosin. On the other hand, the incidences of ejaculatory disorders and intraoperative floppy iris syndrome induced by naftopidil may be lower than for tamsulosin and silodosin having high affinity for the $\alpha 1 \mathrm{~A}$-adrenergic receptor subtype. However, it remains unknown if the efficacy and safety of naftopidil in Japanese is applicable to white, black and Hispanic men having LUTS/BPH in western countries.
\end{abstract}

Keywords: benign prostatic hyperplasia, lower urinary tract symptoms, $\alpha 1$-blocker, naftopidil

\section{Introduction}

Benign prostatic hyperplasia (BPH) is a histological condition that is commonly observed in elderly men. ${ }^{1} \mathrm{BPH}$ is an adenoma composed of a mixture of increased numbers of epithelial and/or stromal cells. Benign enlargement of the prostate (BPE) due to $\mathrm{BPH}$ induces bladder outlet obstruction (BOO) and results in the development of lower urinary tract symptoms (LUTS). There are two mechanisms involved in the development of BOO: mechanical obstruction due to increased volume of the prostate; and functional obstruction due to increased tone of the prostatic smooth muscle. In addition, $\mathrm{BOO}$ secondarily affects bladder function. Either detrusor overactivity during the filling phase or detrusor underactivity during the voiding phase, or a combination of both conditions, modifies LUTS in elderly men with BOO.

There are two mainstays of medical treatment for LUTS suggestive of BPH (LUTS/ $\mathrm{BPH}$ ): $5 \alpha$-reductase inhibitors (5ARI); and $\alpha 1$-adrenergic receptor (AR) antagonists ( $\alpha 1$-blockers). ${ }^{2}$ 5ARI (finasteride, dutasteride) improve BOO through reduction of the prostate volume and contribute to gradual improvement of LUTS and long-term inhibition of disease progression. On the other hand, $\alpha 1$-blockers improve BOO through a decrease of tone of the prostatic smooth muscle. Several $\alpha 1$-blockers are clinically available, including those having nonspecific affinity for $\alpha 1$-AR subtypes 
(prazosin, terazosin, doxazosin, alfuzosin) and those having specific affinity for them (tamsulosin, naftopidil, silodosin). Although several large-scale studies ${ }^{3-5}$ have demonstrated recently that combination of a $5 \mathrm{ARI}$ and $\alpha 1$-blocker is superior to either $5 \mathrm{ARI}$ or $\alpha 1$-blocker monotherapy in terms of improvement of subjective and objective urinary symptoms as well as the long-term inhibition of BPH-related events such as acute urinary retention and conversion to surgical treatment, $\alpha 1$-blockers are still essential as first-line medical treatments for patients having LUTS/BPH with problems, because symptomatic improvement can be achieved rapidly with $\alpha 1$-blockers.

Naftopidil, with three times greater affinity for $\alpha 1 \mathrm{D}$ than for the $\alpha 1 \mathrm{~A}-\mathrm{AR}$ subtype, is an $\alpha 1$-blocker that has been approved for clinical use for LUTS/BPH only in Japan since $1999 .{ }^{6}$ Two Japanese clinical guidelines, the Clinical Guideline for Male Lower Urinary Tract Symptoms ${ }^{7}$ and Clinical Guideline for Benign Prostatic Hyperplasia, ${ }^{8}$ recommend the use of naftopidil for male LUTS/BPH as a grade A recommendation. At present, naftopidil has the second highest use, following tamsulosin, in Japan. However, due to the limited number of English reports on naftopidil and doctors being unable to use it in other countries, the clinical characteristics of this drug have not been sufficiently introduced. Although the English literature on naftopidil up to January 2009 was comprehensively summarized in a review article written by Garimella et al, ${ }^{9}$ several important studies written in Japanese were missed because only reports published in English were reviewed. In this article, the efficacy and safety of naftopidil for LUTS/BPH are reviewed based on the English literature published up to March 2011 as well as several important Japanese reports such as the results of a randomized placebo-controlled trial conducted in Japan.

\section{Pharmacological characteristics of naftopidil}

Naftopidil (( \pm )-1-[4-(2-methoxyphenyl)piperazinyl]-3(1-naphthyloxy) propan-2-ol, Figure 1) is an $\alpha 1$-blocker produced by Boehringer Mannheim, Germany. In vitro study has shown that naftopidil binds to $\alpha 1-\mathrm{AR}$ in human $\mathrm{BPH}$ tissue. ${ }^{10}$ It has a threefold higher affinity for $\alpha 1 \mathrm{D}$ than for the $\alpha 1 \mathrm{~A}-\mathrm{AR}$ subtype, whereas tamsulosin and silodosin have threefold and 56-fold higher affinities for the $\alpha 1 \mathrm{~A}-\mathrm{AR}$ subtype than for the $\alpha 1 \mathrm{D}$ subtype, respectively (Table 1). ${ }^{6,11}$ In an in vivo study using anesthetized male mongrel dogs, not only prostatic pressure but also blood pressure increased by phenylephrine was significantly decreased by intravenous administration of naftopidil in a dose-dependent manner. The

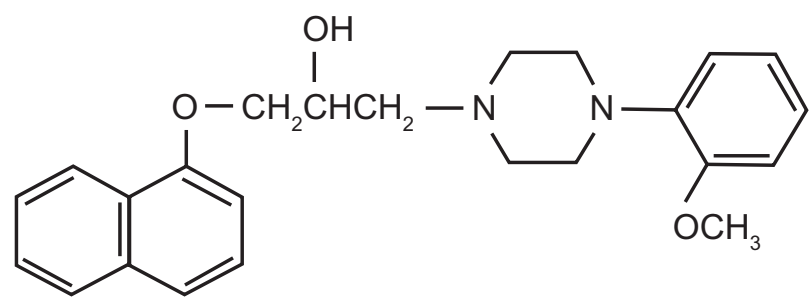

Figure I Chemical structure of naftopidil $\left(\mathrm{C}_{24} \mathrm{H}_{28} \mathrm{~N}_{2} \mathrm{O}_{3}\right)$, molecular weight 392.5 .

inhibition of prostatic pressure was more remarkable than that of blood pressure. ${ }^{6}$ Thus, as it appeared to be a promising $\alpha 1$-blocker with selectivity for the prostate, a phase I clinical study of naftopidil was conducted. ${ }^{12}$ Naftopidil, 12.5 to $100 \mathrm{mg}$, was given to 15 healthy adult Japanese male volunteers. With a single administration of $50 \mathrm{mg}$ of naftopidil after food, the means \pm standard deviations of $\mathrm{T}_{\text {max }}$ (hour), $\mathrm{C}_{\text {max }}$ (ng/mL), $\mathrm{T}_{1 / 2 \beta}$ (hour), $\mathrm{AUC}_{0-\infty}$ (ng $\cdot$ hour/mL) and Clt (L/hour) were $2.20 \pm 1.04,58.6 \pm 24.2,13.2 \pm 5.4,311.6 \pm 54.3$ and $164.2 \pm 26.9$, respectively. The recovery of the intact form of naftopidil in urine was not more than $0.01 \%$. Although there were no abnormal findings in clinical laboratory tests, 4 of the 5 subjects who received a single administration of $100 \mathrm{mg}$ of naftopidil reported headaches, cold sweats, facial pallor, sleepiness and postural hypotension. Naftopidil is excreted into bile after being primarily metabolized by CYP2C9 and CYP3A4 in the liver microsomes. ${ }^{13}$

\section{Rationale for naftopidil treatment of LUTS suggestive of BPH}

Different from tamsulosin and silodosin, which have higher and extremely higher affinity for the $\alpha 1 \mathrm{~A}-\mathrm{AR}$ subtype than for the $\alpha 1 \mathrm{D}$-AR subtype, respectively, naftopidil has distinct characteristics because it has threefold affinity for the $\alpha 1 \mathrm{D}$ subtype than for the $\alpha 1 \mathrm{~A}-\mathrm{AR}$ subtype. ${ }^{6,11}$ Since the tissue of BPH shows nine- and threefold increased expression of mRNA of $\alpha 1 \mathrm{~A}$ and $\alpha 1 \mathrm{D}-\mathrm{AR}$ subtypes, respectively, compared to normal prostatic tissue, ${ }^{14}$ it has been speculated that not only $\alpha 1 \mathrm{~A}$ but also $\alpha 1 \mathrm{D}-\mathrm{AR}$ contributes to contraction of

Table I Affinities of naftopidil, tamsulosin and silodosin to cloned human $\alpha \mathrm{I}$-adrenergic receptors ${ }^{6,11}$

\begin{tabular}{cccc}
\hline & \multicolumn{1}{l}{$\mathbf{K i}(\mathbf{n M})$} & \\
\cline { 2 - 4 } & $\alpha \mathbf{l a}$ & $\alpha \mathbf{l b}$ & $\alpha \mathbf{l d}$ \\
\hline Takei et al $^{6}$ & $3.7 \pm 0.6$ & $20 \pm 1$ & $1.2 \pm 0.0$ \\
$\quad \begin{array}{l}\text { Naftopidil } \\
\text { Tamsulosin }\end{array}$ & $0.019 \pm 0.002$ & $0.29 \pm 0.02$ & $0.063 \pm 0.01 \mathbf{I}$ \\
$\begin{array}{c}\text { Shibata et al" } \\
\text { Silodosin }\end{array}$ & $0.036 \pm 0.010$ & $21 \pm 5$ & $2.0 \pm 0.4$ \\
\hline
\end{tabular}


prostatic smooth muscle. Recently, an interesting observation was reported by Kojima et al. ${ }^{15}$ The expression of mRNA of the $\alpha 1-\mathrm{AR}$ subtype in the prostate biopsy specimens of 61 patients having LUTS/BPH was investigated using quantitative reverse transcriptase-polymerase chain reaction. Of the 61 prostates, $34(55.7 \%)$ and $27(44.3 \%)$ had dominant expression of $\alpha 1 \mathrm{a}$ and $\alpha 1 \mathrm{~d}$, respectively. As discussed in detail later, tamsulosin and naftopidil were more effective in patients with dominant expression of $\alpha 1 \mathrm{a}$ and $\alpha 1 \mathrm{~d}$, respectively. Thus, in approximately half of the patients having LUTS/BPH, the efficacy of the $\alpha 1 \mathrm{D} / \alpha 1 \mathrm{~A}$ blocker naftopidil may be more promising than that of the $\alpha 1 \mathrm{~A} / \alpha 1 \mathrm{D}$ blocker tamsulosin.

The $\alpha 1 \mathrm{D}-\mathrm{AR}$ subtype may be involved in detrusor overactivity associated with $\mathrm{BOO}$ causing overactive bladder syndrome (OAB), since increased expression of mRNA of the $\alpha 1 \mathrm{D}-\mathrm{AR}$ subtype in human detrusor muscle and human lumbosacral spinal cord has been demonstrated. ${ }^{16,17}$ Several animal studies using rats and mice have demonstrated that the micturition reflex is facilitated by the $\alpha 1 \mathrm{D}$-AR subtype on urothelial cells. ${ }^{18,19}$ In addition, it has been demonstrated that naftopidil has an inhibitory effect on C-fiber afferents because the drug increases bladder capacity in rats with cerebral infarction, but not in $\mathrm{C}$-fiber desensitized rats with cerebral infarction. ${ }^{20}$ Thus, naftopidil, with a higher affinity for the $\alpha 1 \mathrm{D}$-AR subtype, may contribute to improving detrusor overactivity through the blockade of the $\alpha 1 \mathrm{D}-\mathrm{AR}$ subtype not only in the prostate but also in nonprostatic organs.

\section{Dose-finding study and randomized placebo-controlled study conducted in Japan}

After the phase I clinical study, ${ }^{12}$ a late phase II clinical study was conducted to determine the efficacy, safety and optimal dosage of naftopidil. ${ }^{21}$ In the study, naftopidil was given to 133 patients with LUTS/BPH. After a 1-week run-in period using a placebo, $25 \mathrm{mg}$ /day naftopidil was given for 2 weeks, then the dosage was escalated to $50 \mathrm{mg}$ /day and given for the next 2 weeks. If the efficacy of $50 \mathrm{mg} /$ day naftopidil was insufficient based on the assessment of investigators, the dosage was escalated to $75 \mathrm{mg}$ /day and given for an additional 2 weeks $(n=47)$. Dose-dependent improvements of LUTS and the maximum flow rate $\left(\mathrm{Q}_{\max }\right)$ were observed. Although 3 patients $(2.3 \%)$ reported adverse events, no serious adverse events were observed. The buzzing or lightheadedness in 2 patients with $25 \mathrm{mg}$ /day naftopidil, and hypotension in 1 patient with $50 \mathrm{mg} /$ day naftopidil spontaneously disappeared after termination or dose reduction of naftopidil. Thus, the optimal dosage is thought to be $25 \mathrm{mg}$ to $75 \mathrm{mg} /$ day.

Yasuda et al evaluated the urodynamic effect of naftopidil using a pressure-flow study. ${ }^{22}$ Naftopidil, 25 to $75 \mathrm{mg} /$ day, was given to 32 patients aged 52 to 78 years (mean 66.3 years) with LUTS/BPH for 4 to 6 weeks. Before and after treatment, uroflowmetry, determination of post-void residual urine (PVR), urethral pressure profile, filling cystometry and pressure-flow study were performed. The mean $\mathrm{Q}_{\max }$ $(\mathrm{n}=28)$ and PVR $(\mathrm{n}=28)$ significantly increased from 9.9 to $14.3 \mathrm{~mL} /$ second $(P<0.001)$ and decreased from 48.1 to $19.3 \mathrm{~mL}(P<0.05)$, respectively. The mean urethral pressure profile $(n=14)$ and cystometry $(n=23)$ showed a significant decrease of maximum urethral closure pressure from 69.0 to $58.8 \mathrm{~cm} \mathrm{H} \mathrm{H}_{2} \mathrm{O}(P<0.05)$ and an increase of the first desire to void from 193.5 to $238.7 \mathrm{~mL}(P<0.05)$, respectively. Although the mean opening pressure and pressure at the maximum flow rate in the pressure-flow study $(\mathrm{n}=14) \mathrm{did}$ not change significantly, from 59.9 to $71.9 \mathrm{~cm} \mathrm{H}_{2} \mathrm{O}$ and 73.5 to $71.5 \mathrm{~cm} \mathrm{H}_{2} \mathrm{O}$, respectively, the mean minimum urethral resistance significantly decreased from 1.7 to $0.9(P<0.05)$. Thus, it is likely that naftopidil urodynamically improves $\mathrm{BOO}$ induced by BPH.

A double-blind randomized placebo-controlled trial was conducted between 1993 and 1995 in Japan. ${ }^{23}$ Although the results were reported in Japanese in 1997, it remains the only randomized placebo-controlled trial. Based on the results of a double-blind study comparison with prazosin hydrochloride, ${ }^{24}$ naftopidil was approved by the Japanese Regulatory Authority for treatment for LUTS/BPH in 1999. In the double-blind randomized placebo-controlled trial, ${ }^{23}$ 333 patients having LUTS/BPH were randomly allocated into 4 groups after at least a 1-week run-in period using a placebo, a placebo for 4 weeks (placebo group, $n=79$ ), $25 \mathrm{mg}$ /day naftopidil for 4 weeks (25 $\mathrm{mg}$ group, $\mathrm{n}=86$ ), $25 \mathrm{mg}$ /day naftopidil for 1 week followed by $50 \mathrm{mg} /$ day naftopidil for 3 weeks (50 mg group, $\mathrm{n}=86$ ), and $25 \mathrm{mg} /$ day naftopidil for 1 week followed by $75 \mathrm{mg}$ /day naftopidil for 3 weeks ( $75 \mathrm{mg}, \mathrm{n}=82$ ). Although changes in LUTS were not evaluated by the International Prostatic Symptom Score (IPSS) because it was not validated in Japanese at that time, improvements of the subjective urinary symptoms and $\mathrm{Q}_{\max }$ in the $50 \mathrm{mg}$ and the $75 \mathrm{mg}$ groups were significantly superior to the placebo group. There was no significant difference in the development of adverse events among the groups. Thus, $50 \mathrm{mg}$ and $75 \mathrm{mg}$ of naftopidil were recommended as the standard dosages for treatment of LUTS/ $\mathrm{BPH}$ in Japan. 


\section{Randomized comparative studies of naftopidil compared with other $\alpha \mathrm{I}$-blockers and phytotherapy}

There are 8 randomized studies of naftopidil compared with other $\alpha 1$-blockers (tamsulosin in 6 , tansulosin and silodosin in 1) and phytotherapy (1) in the contemporary English literature using the IPSS for evaluation of LUTS after 2003 (Table 2). ${ }^{25-32}$ They consist of various inclusion criteria, study designs, treatment durations and analytical methods. A crossover design was applied to 3 studies. ${ }^{25,28,29}$ Most of the studies recruited small numbers of patients without provision of the required sample size for the hypothesis test.

Ikemoto et al reported the efficacy of tamsulosin and naftopidil for 96 patients having LUTS/BPH with IPSS $\geq 8$ and $\mathrm{Q}_{\max }<12 \mathrm{~mL} /$ second. $^{25}$ The 96 patients were randomly allocated into 2 groups. The naftopidil-to-tamsulosin group (N-T group, $\mathrm{n}=43$ ) received $50 \mathrm{mg} /$ day naftopidil for 8 weeks ( $25 \mathrm{mg} /$ day for the first 2 weeks) immediately followed by $0.2 \mathrm{mg} /$ day tamsulosin, which is the approved optimal dosage for treatment of LUTS suggestive of BPH in Japan, for 8 weeks. The tamsulosin-to-naftopidil group (T-N group, $\mathrm{n}=53$ ) received $0.2 \mathrm{mg} /$ day tamsulosin for 8 weeks and then $50 \mathrm{mg} /$ day naftopidil for 8 weeks ( $25 \mathrm{mg} /$ day for the first 2 weeks) without a washout period between the 2 drugs. Twelve (28\%) and 18 patients (34\%) in the N-T and the T-N groups were withdrawn for several reasons including non-attendance at hospital appointments and adverse events. There was no significant difference in the incidence of adverse events between the 2 groups (3\% versus $2 \%$ ). The mean IPSS significantly decreased from 17.0 at baseline to 8.5 at 16 weeks and 17.5 at baseline to 9.2 at 16 weeks in the N-T and the T-N groups, respectively. Storage symptoms such as daytime frequency, urgency, and nocturia were significantly improved only by naftopidil monotherapy, whereas voiding symptoms such as intermittency and straining were improved only by tamsulosin monotherapy. The QOL index and $\mathrm{Q}_{\max }$ showed similar improvements in both groups. In 28 patients who reported "not effective" or "worse" for the initial treatment, the IPSS was improved by crossover to the other drug in 10 of the 12 patients in the N-T group and 16 of the 16 patients in the T-N group. Thus, their study demonstrated that a second $\alpha 1$-blocker may be effective even if the first $\alpha 1$-blocker is ineffective.

Yamanishi et al compared the clinical and urodynamic effects of naftopidil to those of phytotherapy with eviprostat. ${ }^{26}$ Forty-nine patients (mean age 67.9 years) having LUTS/ $\mathrm{BPH}$ with IPSS $\geq 8, \mathrm{Q}_{\max } \leq 12 \mathrm{~mL} / \mathrm{second}$, prostate volume $(\mathrm{PV}) \geq 15 \mathrm{~mL}$, and an obstructive or equivocal condition in a pressure-flow study were included in the study. After a 1 -week run-in period, the patients were randomly allocated into naftopidil $(\mathrm{n}=36)$ and eviprostat $(\mathrm{n}=13)$ groups at the ratio $3: 1$. In the naftopidil group, naftopidil was given at a dose of $25 \mathrm{mg} /$ day for 2 weeks, followed by $50 \mathrm{mg} /$ day for 2 weeks, and then $75 \mathrm{mg} /$ day for another 2 weeks if the patients were not satisfied with the improvement of LUTS. In the other group with eviprostat, which is a mixture of plant extracts from Phila umbellata, Populus tremula and Pulsatilla pratensis, and wheat-germ oil, 6 tablets/day were given for 6 weeks. Symptomatic improvements evaluated by the IPSS and QOL index were significantly better in the naftopidil group than in the eviprostat group. Although improvement of $\mathrm{Q}_{\max }$ tended to be better in the naftopidil group, there was no significant difference $(P=0.0886)$. In the pressure-flow study, there was no improvement of detrusor pressure at the maximum flow rate by the treatments (naftopidil group, $-8.9 \mathrm{~cm} \mathrm{H}_{2} \mathrm{O}, P=0.0865$; eviprostat group, $-10.2 \mathrm{~cm} \mathrm{H}_{2} \mathrm{O}$, $P=0.2015$ ). There was no significant difference in the change of detrusor pressure at the maximum flow rate between the groups $(P=0.8879)$. On the other hand, the Abrams-Griffiths number was significantly decreased by naftopidil treatment $(-14.6, P=0.0422)$ but not by eviprostat treatment $(-10.8$, $P=0.1441)$, although no significant intergroup difference was observed $(P=0.7262)$. In the 19 patients having detrusor overactivity at baseline, it disappeared in 3 of the 14 patients $(21 \%)$ in the naftopidil group but in none of the 5 patients in the eviprostat group. Thus, naftopidil was more effective than eviprostat in terms of symptomatic improvement of LUTS/BPH.

Gotoh et al compared the efficacy and safety of naftopidil and tamsulosin in a multicenter randomized trial. ${ }^{27}$ Men aged $\geq 50$ years having LUTS/BPH with IPSS $\geq 8, \mathrm{Q}_{\max }<15 \mathrm{~mL} /$ second, a voided volume of $\geq 150 \mathrm{~mL}$, and $\mathrm{PV} \geq 20 \mathrm{~mL}$, were enrolled in the study. Of the 185 enrolled patients, 144 were eligible for efficacy analysis and randomly allocated into groups receiving $0.2 \mathrm{mg}$ /day tamsulosin for 12 weeks or $25 \mathrm{mg} /$ day naftopidil for 2 weeks followed by $50 \mathrm{mg}$ /day for 10 weeks. The IPSS and QOL index significantly improved in both groups (IPSS, -8.4 in the tamsulosin group, $P<0.001,-5.9$ in the naftopidil group, $P<0.001$; QOL index, -1.4 in the tamsulosin group, $P<0.001,-1.3$ in the naftopidil group, $P<0.001)$. There was no significant difference in the change of the IPSS between the groups at 12 weeks $(P=0.060)$, although the change of the IPSS in the tamsulosin group tended to be larger than with naftopidil. No intergroup differences were observed in any IPSS index after treatment. $Q_{\max }$ was significantly 


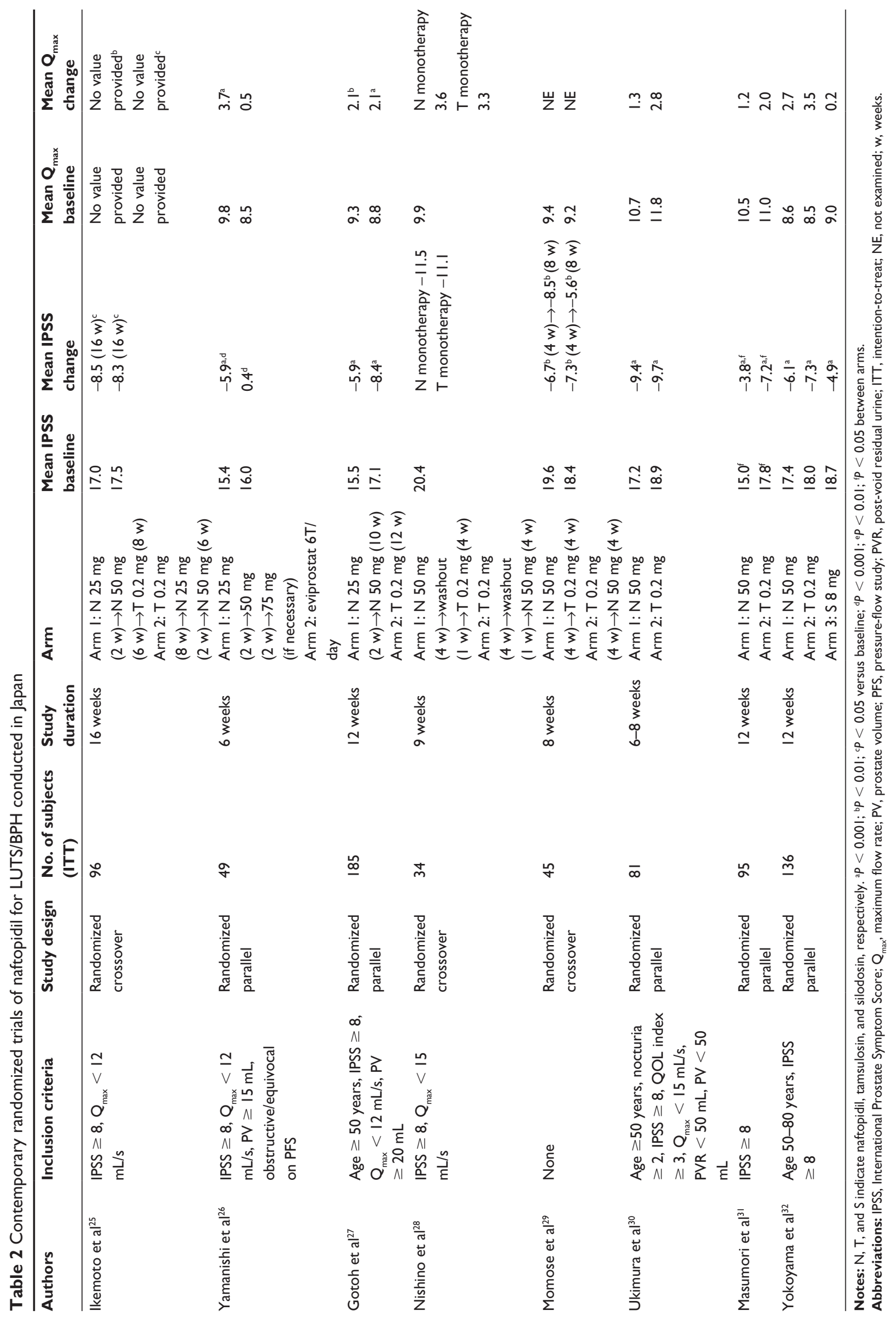


improved by $2.1 \mathrm{~mL} /$ second in both groups $(P<0.001$ and $P=0.001)$ and no intergroup difference after treatment was observed $(P=0.709)$. The adverse events were comparable, with no significant differences in systolic and diastolic blood pressure after treatment between the groups. Thus, the authors concluded that $50 \mathrm{mg}$ of naftopidil was as effective and safe as $0.2 \mathrm{mg}$ of tamsulosin.

Nishino et al investigated the efficacies of naftopidil and tamsulosin in a crossover design. ${ }^{28}$ Thirty-four patients (mean age 72.4 years) having LUTS/BPH with IPSS $\geq 8$ and $\mathrm{Q}_{\max }<15 \mathrm{~mL} /$ second were enrolled in the study. Seventeen patients were initially prescribed $50 \mathrm{mg} /$ day naftopidil for 4 weeks, followed by $0.2 \mathrm{mg} /$ day tamsulosin for 4 weeks after a 1-week washout period. For another 17 patients, tamsulosin was initially prescribed followed by 1 week of washout, and then naftopidil. Thus, all 34 patients received both naftopidil for 4 weeks and tamsulosin for 4 weeks. There was no significant difference in the mean IPSS after treatment between naftopidil (8.9) and tamsulosin monotherapies $(9.3, P=0.265)$. Although there was no significant difference in the mean IPSS voiding symptom subscores after treatment between the groups (3.1 versus 2.6, $P=0.134$ ), the mean IPSS storage symptom subscore after treatment was higher with tamsulosin monotherapy (5.5) than with naftopidil monotherapy (4.8, $P=0.007)$. Of the storage symptoms after treatment, only nocturia showed a significant difference between the groups (2.3 versus $3.1, P<0.001)$. Although no significant difference in the mean $\mathrm{Q}_{\max }$ after treatment was observed between naftopidil monotherapy ( $13.5 \mathrm{~mL} /$ second $)$ and tamsulosin monotherapy (13.2 $\mathrm{mL} / \mathrm{second}$ ), the mean detrusor pressure at the maximum flow rate in the pressure-flow study after treatment was lower for tamsulosin monotherapy $\left(61.2 \mathrm{~cm} \mathrm{H}_{2} \mathrm{O}\right)$ than for naftopidil monotherapy $\left(64.3 \mathrm{~cm} \mathrm{H}_{2} \mathrm{O}, P=0.002\right)$. On the other hand, the mean first desire to void and mean maximum desire to void were significantly higher with naftopidil monotherapy $(188.4 \mathrm{~mL}, 339.4 \mathrm{~mL})$ than with tamsulosin monotherapy (174.1 mL, $P<0.001 ; 334.9 \mathrm{~mL}, P=0.036)$. Detrusor overactivity disappeared in 2 patients with naftopidil but not in those with tamsulosin. The authors concluded that naftopidil was better than tamsulosin for improvement of storage symptoms, especially nocturia, as a result of the disappearance of detrusor overactivity and increase in the first desire to void.

Momose et al also reported the results of crossover between naftopidil and tamsulosin. ${ }^{29}$ Forty-five patients (mean age 66.9 years) having LUTS/BPH were included in the study. There were no symptomatic severity criteria for inclusion. The patients were randomly assigned to the N-T group $(\mathrm{n}=20,50 \mathrm{mg}$ of naftopidil for 4 weeks followed by $0.2 \mathrm{mg} /$ day tamsulosin for 4 weeks) and T-N group $(\mathrm{n}=25,0.2 \mathrm{mg} /$ day tamsulosin for 4 weeks followed by $50 \mathrm{mg}$ of naftopidil for 4 weeks). Although the IPSS was similarly improved during the first treatment period in both groups (19.6 to 12.9 in the N-T group, $P<0.01$; 18.4 to 11.1 in the T-N group, $P<0.01$ ), after crossover the IPSS was slightly improved in the N-T group (12.9 to 11.1) whereas it slightly deteriorated in the T-N group (11.1 to 12.8). Tamsulosin was more effective than naftopidil for intermittency, nocturia, and the QOL index. The authors concluded that the therapeutic effects of $0.2 \mathrm{mg}$ of tamsulosin on storage and voiding symptoms were superior to those of naftopidil.

Ukimura et al directly compared the efficacy of naftopidil and tamsulosin in patients having LUTS/BPH associated with nocturia. ${ }^{30}$ Patients aged $\geq 50$ years having LUTS/BPH with nocturia $\geq 2$, IPSS $\geq 8$, QOL index $\geq 3, \mathrm{Q}_{\max }<15 \mathrm{~mL} /$ second, with a voided volume of $\geq 150 \mathrm{~mL}$, PVR $<50 \mathrm{~mL}$ and $\mathrm{PV}<50 \mathrm{~mL}$ were randomized into two groups, $50 \mathrm{mg} /$ day naftopidil for $6-8$ weeks $(\mathrm{n}=31)$ and $0.2 \mathrm{mg} /$ day tamsulosin for $6-8$ weeks $(n=28)$. The IPSS was significantly improved in both groups, from 17.2 to $7.8(P=0.0000)$ in the naftopidil group and from 18.9 to $9.2(P=0.0001)$ in the tamsulosin group without a significant intergroup difference at the end of the observation period $(P=0.98)$. The sum of day frequency and nocturia was improved earlier in the naftopidil group ( 7.0 at baseline, 4.4 at 2 weeks, 3.2 at $6-8$ weeks) than in the tamsulosin group (6.8 at baseline, 4.9 at 2 weeks [versus naftopidil, $P=0.0489$ ], 3.7 at $6-8$ weeks [versus naftopidil, $P=0.10])$. There were no significant differences in changes of $\mathrm{Q}_{\max }$ and PVR between the 2 groups. The authors concluded that naftopidil provided early improvements of day frequency and nocturia compared with tamsulosin.

Masumori et al performed a head-to-head comparison of the efficacies of naftopidil and tamsulosin, although the study was conducted to investigate differences in the incidence of ejaculatory disorders as a primary endpoint. Ninety-five men aged $\geq 50$ years (mean 64 years) having LUTS/BPH with IPSS $\geq 8$ were enrolled in the study and randomly assigned to receive $50 \mathrm{mg} /$ day of naftopidil $(\mathrm{n}=48)$ or $0.2 \mathrm{mg} /$ day of tamsulosin $(n=47)$ for 12 weeks. ${ }^{31}$ Although there were no significant differences in the changes in the $\mathrm{Q}_{\max }$ and PVR caused by the treatments between the 2 groups, the changes in the IPSS were significantly higher in the tamsulosin group (from 17.8 to $10.6,-7.2$ ) than in the naftopidil group (from 15.0 to $11.2,-3.8, P=0.013)$. Similarly, the improvement 
in the QOL index in the tamsulosin group (from 4.7 to 2.8, -1.9) was larger than that in the naftopidil group (from 4.2 to $3.2,-1.0, P=0.013)$. Thus, the authors speculated that the efficacy of $0.2 \mathrm{mg}$ of tamsulosin might be better than that of $50 \mathrm{mg}$ of naftopidil.

More recently, Yokoyama et al directly compared the effects of three different types of $\alpha 1$-blockers; naftopidil, tamsulosin, and silodosin, on LUTS, erectile dysfunction, and ejaculatory dysfunction. ${ }^{32}$ A total of 136 patients aged 50-80 years having LUTS/BPH with IPSS $\geq 8$ were enrolled in the study. They were randomly assigned to 3 groups, naftopidil at $50 \mathrm{mg}$ once a day $(\mathrm{n}=46)$, tamsulosin at $0.2 \mathrm{mg}$ once a day $(\mathrm{n}=45)$, or silodosin at $4 \mathrm{mg}$ twice a day $(n=45)$ for 12 weeks. The mean IPSS was significantly improved by treatment for 12 weeks in all 3 groups, from 17.4 to 11.3 in the naftopidil group; 18.0 to 10.7 in the tamsulosin group, and from 18.7 to 13.8 in the silodosin group. No significant difference was observed in the IPSS at 12 weeks among the groups. Similarly, there were no significant differences in the mean QOL index, $\mathrm{Q}_{\max }$, and PVR at 12 weeks among the groups. Thus, the authors concluded that the three $\alpha 1$-blockers similarly provided objective and subjective improvements in LUTS/BPH in the population they investigated.

Based on the results of the previous randomized studies comparing the efficacy of naftopidil to other $\alpha 1$-blockers, mainly tamsulosin, some reports demonstrated the comparative efficacy, ${ }^{25,27,28,30,32}$ whereas others did not, ${ }^{29,31}$ although no study had sufficient statistical power to draw a solid conclusion. Kojima et al clearly showed that the dominant $\alpha 1$-AR subtype varied among individuals. ${ }^{15}$ They performed prostate biopsies for 61 patients having LUTS/BPH and the expression of mRNA in the $\alpha 1-\mathrm{AR}$ subtype in the specimens was analyzed. Naftopidil, $50 \mathrm{mg} /$ day and tamsulosin, $0.2 \mathrm{mg} /$ day were randomly given to 28 and 33 patients for 12 weeks each. In the naftopidil group, $\alpha 1 \mathrm{a}-$ and $\alpha 1 \mathrm{~d}-\mathrm{AR}$ were dominant in the prostates of 12 and 16 patients, respectively. In the tamsulosin group, $\alpha 1 \mathrm{a}-$ and $\alpha 1 \mathrm{~d}-\mathrm{AR}$ were dominant in the prostates of 22 and 11 patients, respectively. There were no significant differences in the efficacies such as the IPSS, QOL index, $\mathrm{Q}_{\max }$, and PVR between the naftopidil and tamsulosin groups. However, in the naftopidil group, improvements of subjective and objective urinary symptoms were more remarkable in the patients with the $\alpha 1 \mathrm{~d}$-AR dominant subtype than in those in whom $\alpha 1 \mathrm{a}-\mathrm{AR}$ was dominant. Conversely, in the tamsulosin group, striking symptomatic improvements were observed in the patients with the $\alpha 1 \mathrm{a}-\mathrm{AR}$ dominant subtype. Thus, the response to $\alpha 1$-blockers may depend on the ratio of the expression level of the $\alpha 1-\mathrm{AR}$ subtype rather than on the type of $\alpha 1$-blocker.

\section{Dose modification study}

Even though $50 \mathrm{mg}$ and $75 \mathrm{mg} /$ day naftopidil were recommended as standard dosages according to the phase III clinical study, ${ }^{23}$ no previous randomized studies allowed dose escalation up to $75 \mathrm{mg}$ or a dosage of $75 \mathrm{mg}$ as the starting dose. Yokoyama et al performed a randomized study to compare the efficacy and safety of $25 \mathrm{mg}$ and $75 \mathrm{mg}$ of naftopidil as the starting doses for patients aged $50-80$ years having LUTS/BPH with IPSS $\geq 8$, QOL index $\geq 2$, nocturia $\geq 3$, and $P V \geq 20 \mathrm{~mL}$ (Table 3). ${ }^{33}$ Naftopidil, $25 \mathrm{mg}(\mathrm{n}=72)$ or $75 \mathrm{mg}(\mathrm{n}=67)$ was randomly administered once a day for 4 weeks. There were no differences in changes of the IPSS and QOL index between the groups. On the other hand, $\mathrm{Q}_{\max }$ at the endpoint was significantly higher in the $75 \mathrm{mg}$ group than in the $25 \mathrm{mg}$ group $(P<0.05)$. In the patients having moderate symptomatic severity, the degree of improvement in voiding symptoms was greater in the $75 \mathrm{mg}$ group than in the $25 \mathrm{mg}$ group $(P<0.05)$. Since there was no significant difference in the incidence of adverse events between $25 \mathrm{mg}$ $(3.9 \%)$ and $75 \mathrm{mg}(2.6 \%)$, they concluded that starting administration of $75 \mathrm{mg} /$ day naftopidil should be considered for patients with moderate symptomatic severity. Kadekawa et al supported the clinical efficacy and safety of a naftopidil dose of $75 \mathrm{mg}$ once a day for 4 weeks. ${ }^{34}$ Interestingly, Tsuritani et al demonstrated in a randomized trial that improvement of the mean IPSS after 8 weeks of treatment was significantly higher for $75 \mathrm{mg}$ once daily in the evening (9.2) than with $25 \mathrm{mg}$ thrice daily $(11.3, P=0.0347)$ and that this was probably due to a difference in $\mathrm{C}_{\max }$ between them. ${ }^{35} \mathrm{~A}$ recent study demonstrated that dose escalation to $75 \mathrm{mg}$ in patients with an insufficient response to $50 \mathrm{mg}$ once a day for 12 weeks (defined as improvement of the IPSS $<5$ ) showed further improvement of subjective and objective urinary symptoms. ${ }^{36}$ On the other hand, Oh-oka reported the results of a dose-reduction study. ${ }^{37}$ For 100 patients having LUTS/ $\mathrm{BPH}$, naftopidil was administrated once in the morning at a dose $75 \mathrm{mg}$ for 6 weeks; then, following washout for 1 week, a reduced dose of $50 \mathrm{mg}$ was administered for another 6 weeks. There was no significant difference in the mean IPSS after treatment between $75 \mathrm{mg}$ (5.2) and $50 \mathrm{mg}$ (5.3), although a significant improvement in urgency was found only after administration of $50 \mathrm{mg}$. In addition, there were no significant differences in objective measurements, including the parameters in a pressure-flow study, except for bladder compliance. Thus, $75 \mathrm{mg}$ of naftopidil is not always superior 


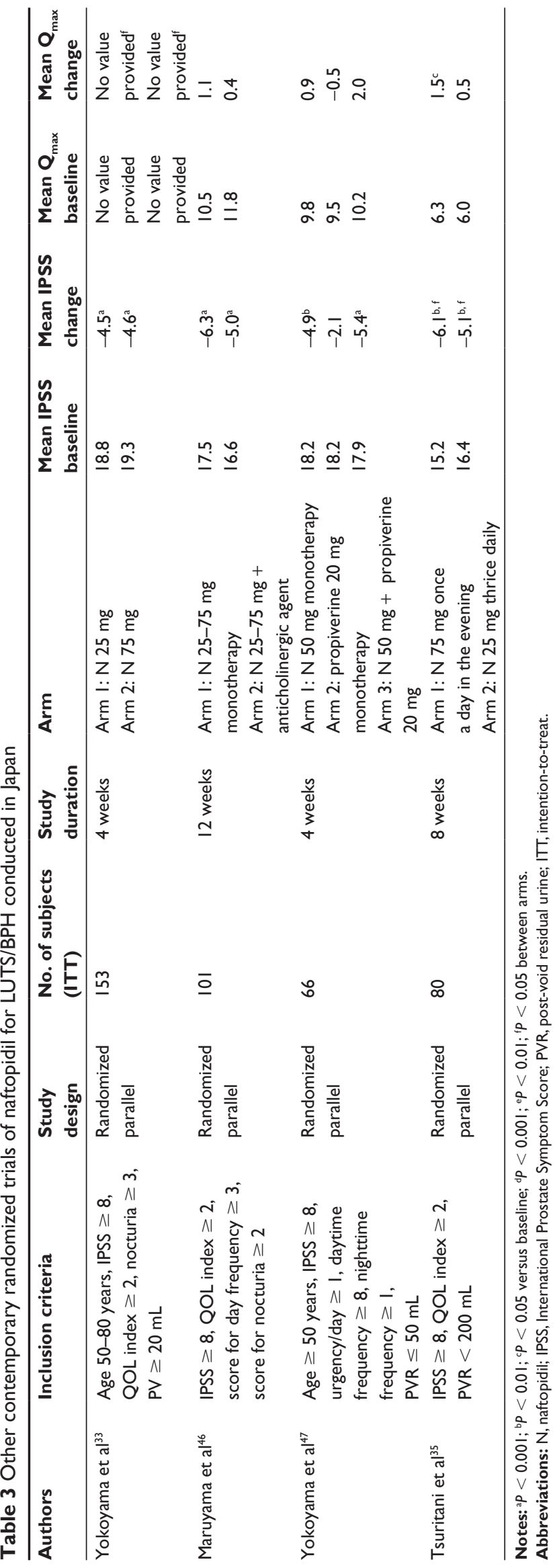

to $50 \mathrm{mg}$ of naftopidil. It is highly likely that the optimal dosage of naftopidil varies among individuals based on different $\alpha 1 \mathrm{~A} / \alpha 1 \mathrm{D}-\mathrm{AR}$ subtype ratios.

\section{Effect of naftopidil on overactive bladder symptoms and nocturia}

Several single-arm studies focused on the efficacy of naftopidil for $\mathrm{OAB}$ and nocturia associated with $\mathrm{BPH} .{ }^{38-41}$ Oh-oka showed that $75 \mathrm{mg}$ of naftopidil was effective to decrease nocturnal frequency in 122 patients with remaining nocturia $\geq 3$ even after treatment using $0.2 \mathrm{mg}$ of tamsulosin for 6 weeks..$^{38}$ Although detrusor overactivity was found in 40 patients, it disappeared in 31 patients after 6 weeks of naftopidil administration. Takahashi et al demonstrated the efficacy of 50-75 mg/day naftopidil for 6 weeks for 81 patients (mean age 69 years) having LUTS/BPH with urgency/day $\geq 1$, IPSS $\geq 8$ and any of the scores for 3 items of the IPSS (day frequency, nocturia, urgency) $\geq 3 .{ }^{39}$ The mean scores for urgency on the IPSS, day frequency and nocturia on the 2-day frequency volume chart decreased from 3.1 to $1.4(P<0.0001), 9.3$ to $8.0(P<0.0001)$, and from 2.7 to $2.0(P<0.0001)$, respectively. Significant improvement of nocturia was observed in both the patients with, and without, nocturnal polyuria. Interestingly, a tendency for nocturnal urine volume to decrease was observed in the patients with nocturnal polyuria (from 919 to $766 \mathrm{~mL}, P=0.101$ ). Thus, naftopidil was effective for nocturia in patients with LUTS regardless of the existence of nocturnal polyuria. Yokoyama et al reported that nocturia was well-controlled by naftopidil treatment, with decreased sleep disturbances. ${ }^{40}$ In addition, they demonstrated that nocturnal urine volume significantly decreased in the sleep disturbance group, perhaps through the central action of naftopidil on vasopressin secretion.

In general, $\alpha 1$-blocker monotherapy is effective to control not only voiding symptoms but also storage symptoms. However, $\alpha 1$-blocker monotherapy does not always control the storage symptoms. Recently, solid evidence to support the efficacy and safety of combination of $\alpha 1$-blockers and anticholinergic agents for male LUTS associated OAB has been reported. ${ }^{42-45}$ Maruyama et al compared the efficacy and safety of naftopidil monotherapy with combination therapy using naftopidil and anticholinergic agents for patients having LUTS/BPH with storage symptoms ${ }^{46}$ Either monotherapy with $25-75 \mathrm{mg}$ of naftopidil $(\mathrm{n}=45)$ or combination therapy using $25-75 \mathrm{mg}$ of naftopidil and an anticholinergic agent (10-20 $\mathrm{mg}$ of propiverine hydrochloride or 2-6 mg of oxybutynin hydrochloride, $\mathrm{n}=41$ ) was randomly given to 101 patients with LUTS/BPH with IPSS $\geq 8$, QOL index $\geq 3$, 
a score for day frequency $\geq 3$, and a score for nocturia $\geq 2$ for 12 weeks. There were no significant differences in the IPSS, QOL index, and $\mathrm{Q}_{\max }$ between the groups after treatment. PVR was significantly worse in the combination group than in the monotherapy group. Thus, clinical usefulness of combination therapy was not found in the study. Yokoyama et al performed a randomized study to compare the efficacy and safety of naftopidil monotherapy $(n=19)$, propiverine monotherapy $(n=18)$ and combination therapy $(n=21)$ for patients having LUTS/BPH associated with OAB (mean age 69.1 years). The IPSS did not improve with the propiverine monotherapy. On a frequency volume chart, although daytime frequency with the naftopidil monotherapy and nighttime frequency with the propiverine monotherapy did not improve, both significantly improved with the combination therapy. On the other hand, PVR significantly increased with the propiverine monotherapy and the combination therapy.

Thus, information on the efficacy and safety of combination therapy using naftopidil and anticholinergic agents is too limited to draw a definitive conclusion. In addition, no studies investigated add-on effects of anticholinergic agents for patients having remaining OAB after naftopidil monotherapy.

\section{Long-term efficacy of naftopidil}

Several studies reported on the long-term efficacy of $\alpha 1$-blockers over 3 years. Narayan et al demonstrated that improvement of LUTS and the flow rate lasted up to 6 years when using $0.4 \mathrm{mg}$ or $0.8 \mathrm{mg}$ of tamsulosin in an open-label extension study. ${ }^{48}$ Schulman et al also reported long-term efficacy of up to 4 years with $0.4 \mathrm{mg}$ of tamsulosin in Europe. ${ }^{49}$ The MTOPS study and the CombAT study also demonstrated the long-term efficacy of doxazosin monotherapy and tamsulosin monotherapy, respectively. ${ }^{3-5}$ However, the long-term efficacy of naftopidil over 1 year has not been investigated well. In addition, information on the rate of treatment failure during long-term follow-up after administration of naftopidil is extremely limited.

Masumori et al examined treatment failure during a 4-year follow-up period after administration of $50 \mathrm{mg}$ /day naftopidil for 247 patients (mean age 67.6 years) having LUTS/BPH with IPSS $\geq 8 .{ }^{50}$ Of the 247 , treatment failure defined as conversion to other medical treatment or surgery occurred in 42 patients $(17.0 \%)$ during the 4-year follow up period. The 4-year treatment failure rate on the KaplanMeier curve was $35.0 \%$. Among the parameters at baseline, PV was the only significant determinant of treatment failure. Patients with a PV of $35 \mathrm{~mL}$ or larger had a 2.1-fold hazard of treatment failure compared to those with a PV of smaller than $35 \mathrm{~mL}(95 \% \mathrm{CI}$; 1.06-4.33, $P=0.03)$. Those patients having severe IPSS at 12 weeks after administration of naftopidil had a 3.5-fold higher hazard than those having mild/moderate IPSS (95\%CI; 1.34-9.26, $P=0.01)$. By 4 years, 200 patients $(81 \%)$ had quit taking naftopidil because of adverse events, treatment failure, loss to follow-up, etc. Thus, only $19 \%$ were known to continue the same medication for 4 years in real-life clinical practice. Although similar results were reported by de la Rosette et al, indicating that the discontinuation rates were $64 \%$ after 3 years and $79 \%$ after 5 years of follow-up after administration of $\alpha 1$-blockers such as terazosin, alfuzosin, and tamsulosin, the discontinuation rate was significantly different according to the type of $\alpha 1$-blocker. ${ }^{51}$ Kawachi et al retrospectively compared the 5 -year failure rates of $25-75 \mathrm{mg} /$ day naftopidil $(\mathrm{n}=78)$ and $0.2 \mathrm{mg}$ of tamsulosin $(\mathrm{n}=53)$ for 131 patients (mean age 66.4 years) having LUTS/BPH with IPSS $\geq 8$ and a QOL index $\geq 3 .{ }^{52}$ No significant difference in failure rates was observed since 28 patients $(35.9 \%)$ using naftopidil and $22(41.4 \%)$ using tamsulosin discontinued treatment during the follow up period. In addition, there were no differences in reasons for discontinuation between the groups. Thus the differences in the long-term outcomes and discontinuation rates should be investigated prospectively.

Kojima et al investigated changes of expression levels of $\alpha 1$-AR subtypes in 15 prostates having LUTS/BPH before and after administration of $50 \mathrm{mg} /$ day naftopidil for 12 weeks. ${ }^{53}$ Naftopidil down-regulated the expression of $\alpha 1 \mathrm{a}-$ and $\alpha 1 b$-AR subtypes whereas it up-regulated the expression of the $\alpha 1 d-A R$ subtype without a change in the total $\alpha 1-A R$ mRNA expression level. Although there was no correlation between the changes of $\alpha 1-A R$ subtype expression levels and the short-term efficacy of naftopidil, its long-term use may induce therapeutic tolerance because up-regulation of the $\alpha 1 \mathrm{~d}-\mathrm{AR}$ subtype is considered a compensatory adaptation to administration of the chronic $\alpha 1 \mathrm{D}-\mathrm{AR}$ antagonist naftopidil.

\section{Sexual dysfunction and intraoperative floppy iris syndrome}

One of the adverse events induced by $\alpha 1$-blockers is ejaculatory disorders. The induction of ejaculatory disorders by $\alpha 1$-blockers may be determined by the selectivity for the $\alpha 1 \mathrm{~A}-\mathrm{AR}$ subtype. Hisasue et al demonstrated that $\alpha 1 \mathrm{~A}$ is the dominant subtype in human seminal vesicles $(\alpha 1 \mathrm{a}$, $75.0 \% ; \alpha 1 \mathrm{~d}, 13.3 \% ; \alpha 1 \mathrm{~b}, 11.7 \%) .{ }^{54}$ In addition, the study of 17 healthy Japanese volunteers showed that 0.2 or $0.4 \mathrm{mg}$ 
of tamsulosin for 3 days resulted in a reduced amount of semen, whereas 50 or $100 \mathrm{mg}$ of naftopidil for 3 days did not. Since no sperm were detected in the postejaculate midstream urine, the ejaculatory dysfunction induced by tamsulosin is thought to be due to inhibition of seminal emission rather than retrograde ejaculation. Thus, a drug that has higher selectivity for the $\alpha 1 \mathrm{~A}-\mathrm{AR}$ subtype seems to easily cause ejaculatory dysfunction, mainly through the inhibition of seminal emission.

Masumori et al performed a randomized prospective study to investigate the incidence of ejaculatory disorders caused by $50 \mathrm{mg}$ of naftopidil $(\mathrm{n}=48)$ and $0.2 \mathrm{mg}$ of tamsulosin $(\mathrm{n}=47)$. Among men who had sexual activity during the 12 weeks, the proportion who reported an abnormal feeling on ejaculation was higher in the tamsulosin group (16.7\%) than in the naftopidil group (7.4\%), although the difference was not significant $(P=0.402)$. The proportion of men who reported reduced ejaculatory volume after treatment was significantly higher in the tamsulosin group (96.0\%) than in the naftopidil group (73.1\%, $P=0.0496)$. Although the improvement of erectile function by $\alpha 1$-blockers has been reported, ${ }^{55,56}$ no significant change in the International Index of Erectile Function (IIEF)-5 score caused by either drug was observed in this small study. On the other hand, Yokoyama et al showed that the mean IIEF-5 score improved in a nafopidil group ( 7.0 at baseline to 7.6 at 3 months, $P=0.013)$ but not in a silodosin group (6.2 at baseline to 5.0 at 3 months, $P=0.682$ ) or tamsulosin group (6.6 at baseline to 5.2 at 3 months, $P=0.342$ ). ${ }^{32}$ The proportion of newly developed reduced volume of ejaculation was relatively high in the silodosin group (10/41, 24.4\%). However, there was no significant difference between naftopidil (1/42, $2.4 \%)$ and tamsulosin $(1 / 39,2.6 \%)$. Thus, naftopidil may be applicable for relatively young patients who are sexually active and want to avoid ejaculatory disorders.

Intraoperative floppy iris syndrome (IFIS) has been reported as one of the adverse events of $\alpha 1$-blockers. The FDA issued a labeling change for tamsulosin warning of the possibility of IFIS in 2005. There is a prospective multicenter study that investigated the incidence of IFIS. ${ }^{57}$ In 2,643 consecutive eyes of 1,968 patients $(1,015$ eyes of 762 male patients and 1,628 eyes of 1,206 female patients) who received cataract surgery, IFIS was observed in 29 eyes (1.1\%) of 25 male patients, all of whom were receiving systemic $\alpha 1$ blockers. Of the 58 eyes of 50 patients who took tamsulosin, 25 eyes (43.1\%) developed IFIS. Of the 21 eyes of 19 patients receiving naftopidil, IFIS was observed in 4 eyes $(19.0 \%)$. Thus, the incidence of IFIS was significantly higher with tamsulosin than with naftopidil $(P=0.042)$.
On the other hand, no IFIS was observed in patients using nonselective $\alpha 1$-blockers such as prazosin and terazosin. Thus, $\alpha 1$-blockers having higher affinity for the $\alpha 1 \mathrm{~A}-\mathrm{AR}$ subtype are likely to cause IFIS as well as ejaculatory disorders.

\section{QOL and naftopidil}

Two studies mainly investigated QOL using a questionnaire. Komiya et al demonstrated that LUTS/BPH impaired generic QOL evaluated by the Short Form-8 (SF-8), that was improved by naftopidil treatment. ${ }^{58}$ Awa et al showed that naftopidil significantly improved 7 domains, though not general health perceptions and social limitations, in the King's Health Questionnaire (KHQ) having 9 domains consisting of 21 questions. ${ }^{59}$

\section{Conclusions}

Naftopidil is clinically available only in Japan. There are no data derived from white or black men living in western countries. Thus, it remains unknown if the efficacy and safety of naftopidil in the Japanese and Asian population are applicable to others. In addition, well-designed prospective large-scale clinical studies having adequate statistical power to draw solid conclusions are lacking. On the other hand, the possible low incidence of sexual dysfunction caused by naftopidil is attractive. Further comparative short-term and long-term studies including evaluation of sexual function are mandatory. In addition, studies in real life clinical practice are necessary to apply the results obtained by randomized controlled studies to the general population.

\section{Disclosure}

The author reports no conflict of interest in this work.

\section{References}

1. Abrams P, D'Ancona C, Griffiths S, et al. Lower urinary tract symptom: etiology, patient assessment and predicting outcome from therapy. In: McConnell J, Abrams P, Denis L, Khoury S, Roehrborn C, editors. Male Lower Urinary Tract Dysfunction Evaluation and Management, Ed 21. Paris: Health Publications; 2006:69-142.

2. Chapple C, Artibani W, Berges R, et al. New medical developments in the management of LUTS in adult men. In: McConnell J, Abrams P, Denis L, Khoury S, Roehrborn C, editors. Male Lower Urinary Tract Dysfunction Evaluation and Management, Ed 21. Paris: Health Publications; 2006:143-194.

3. McConnell JD, Roehrborn CG, Bautista OM, et al. The long-term effect of doxazosin, finasteride, and combination therapy on the clinical progression of benign prostatic hyperplasia. $N$ Engl J Med. 2003; 349(25):2387-2398.

4. Roehrborn CG, Siami P, Barkin J, et al. The effects of dutasteride, tamsulosin and combination therapy on lower urinary tract symptoms in men with benign prostatic hyperplasia and prostatic enlargement: 2-year results from the CombAT study. J Urol. 2008;179(2):616-621. 
5. Roehrborn CG, Siami P, Barkin J, et al. The effects of combination therapy with dutasteride and tamsulosin on clinical outcomes in men with symptomatic benign prostatic hyperplasia: 2-year results from the CombAT study. Eur Urol. 2010;57(1):123-131.

6. Takei R-I, Ikegaki I, Shibata K, Tsujimoto G, Asano T. Naftopidil, a novel $\alpha 1$-adrenoceptor antagonist, displays selective inhibition of canine prostatic pressure and high affinity binding to cloned human

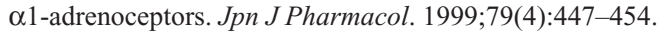

7. Homma Y, Araki I, Igawa Y, et al. Japanese Society of Neurogenic Bladder. Clinical guideline for male lower urinary tract symptoms. Int J Urol. 2009;16(10):775-790.

8. Homma Y, Ishizuka O, Ozono S, et al. Clinical Guideline for Benign Prostatic Hyperplasia. Tokyo: RichHill Medical Inc.; 2011.

9. Garimella PS, Fink HA, MacDonald R, Wilt TJ. Naftopidil for the treatment of lower urinary tract symptoms compatible with benign prostatic hyperplasia. Cochrane Database Syst Rev. 2009;Oct 7(4):CD007360.

10. Yamada S, Suzuki M, Kato Y, et al. Binding characteristics of naftopidil and $\alpha 1$-adrenoceptor antagonists to prostatic $\alpha$-adrenoceptors in benign prostatic hypertrophy. Life Sci. 1992;50(2):127-135.

11. Shibata K, Foglar R, Horie K, et al. KMD-3213, a novel, potent, alpha 1a-adrenoceptor-selective antagonist: characterization using recombinant human alpha 1-adrenoceptors and native tissues. Mol Pharmacol. 1995;48(2):250-258.

12. Nakashima M, Kanamaru M, Uematsu T. Phase I clinical study of naftopidil (KT-611), a new $\alpha 1$-adrenoceptor blocker. $J$ Clin Therap Med. 1992;8 Suppl 3:63-81.

13. Miyanaga H, Sakamoto F, Suzuki T, Adachi Y, Shimada N. Identification of human P450 isozymes involved in the metabolism of naftopidil (KT-611) and effect of naftopidil (KT-611) on the enzyme activities of human P450. Iyakuhin Kenkyu. 1999;30:447-456.

14. Nasu K, Moriyama N, Kawabe K, et al. Quantification and distribution of $\alpha 1$-adrenoceptor subtype mRNAs in human prostate: comparison of benign hypertrophied tissue and non-hypertrophied tissue. Br J Pharmacol. 1996;119(5):797-803.

15. Kojima Y, Sasaki S, Kubota Y, et al. Expression of $\alpha 1$-adrenoceptor subtype mRNA as a predictor of the efficacy of subtype selective $\alpha 1$-adrenoceptor antagonists in the management of benign prostatic hyperplasia. J Urol. 2008;179(3):1040-1046.

16. Malloy BJ, Price DT, Price RR, et al. Alpha 1 adrenergic receptor subtypes in human detrusor. $J$ Urol. 1998;160(3 Pt 1):937-943.

17. Smith MS, Schambra UB, Wilson KH, Page SO, Schwinn DA. Alpha 1-adrenergic receptors in human spinal cord: specific localized expression of mRNA encoding alpha 1-adrenergic receptor subtypes at four distinct levels. Mol Brain Res. 1999;63(2):254-261.

18. Ishihama H, Momota Y, Yanase H, Wang X, de Groat WC, Kawatani M. Activation of alpha 1D adrenergic receptors in the rat urothelium facilitates the micturition reflex. J Urol. 2006;175(1):358-364.

19. Wang X, Matsumoto-Miyai K, Yoshizumi M, et al. Urothelial $\alpha 1 \mathrm{D}$ receptor is predominantly involved in the adrenergic facilitation of micturition reflex. LUTS. 2009;1 (Suppl 1):S10-S14.

20. Yokoyama O, Yusup A, Oyama N, et al. Improvement of bladder storage function by a1-blocker depends on the suppression of C-fiber afferent activity in rats. Neurourol Urodyn. 2006;25:461-467.

21. Fukaya Y, Shiraiwa Y, Yamaguchi O, et al. Dose-finding study of naftopidil (KT-611) for bladder outlet obstruction caused by benign prostatic hypertrophy. Nishinihon J Urol. 1992;54:697-710.

22. Yasuda K, Yamanishi T, Tojo M, Nagashima K, Akimoto S, Shimazaki J. Effect of naftopidil on urethral obstruction in benign prostatic hyperplasia: assessment by urodynamic studies. Prostate. 1994;25(1):46-52.

23. Yamaguchi O, Fukaya Y, Shiraiwa Y, et al. Dose-dependent effects and clinical usefulness of naftopidil (KT-611) on urinary obstruction caused by benign prostatic hyperplasia: double-blind comparative study compared with placebo. Clin Rep. 1997;31:1315-1360.

24. Yamaguchi O, Fukaya Y, Shiraiwa Y, et al. Clinical evaluation of naftopidil (KT-611) on urinary obstruction caused by benign prostatic hypertrophy: double-blind comparative study compared with prazosin hydrochloride. J Clin Ther Med. 1992;8:699-722.
25. Ikemoto I, Kiyota H, Ohishi Y, et al. Usefulness of tamsulosin hydrochloride and naftopidil in patients with urinary disturbance caused by benign prostatic hyperplasia: a comparative, randomized, two-drug crossover study. Int J Urol. 2003;10(11):587-594.

26. Yamanishi T, Yasuda K, Kamai T, et al. Single-blind, randomized controlled study of the clinical and urodynamic effects of an alpha-blocker (naftopidil) and phytotherapy (eviprostat) in the treatment of benign prostatic hyperplasia. Int J Urol. 2004;11(7):501-509.

27. Gotoh M, Kamihira O, Kinukawa T, Ono Y, Ohshima S, Origasa H. Comparison of tamsulosin and naftopidil for efficacy and safety in the treatment of benign prostatic hyperplasia: a randomized controlled trial. BJU Int. 2005;96(4):581-586.

28. Nishino Y, Masue T, Miwa K, Takahashi Y, Ishihara S, Deguchi T. Comparison of two alpha1-adrenoceptor antagonists, naftopidil and tamsulosin hydrochloride, in the treatment of lower urinary tract symptoms with benign prostatic hyperplasia: a randomized crossover study. BJU Int. 2006;97(4):747-751.

29. Momose H, Hosokawa Y, Kishino T, Ono T, Oyama N. Crossover comparison study on the therapeutic effects of tamsulosin hydrochloride and naftopidil in lower urinary tract symptoms associated with benign prostatic hyperplasia. Drugs Today(Barc). 2007;43 Suppl A:1-10.

30. Ukimura O, Kanazawa M, Fujihara A, Kamoi K, Okihara K, Miki T. Naftopidil versus tamsulosin hydrochloride for lower urinary tract symptoms associated with benign prostatic hyperplasia with special reference to the storage symptom: a prospective randomized controlled study. Int J Urol. 2008;15(12):1049-1054.

31. Masumori N, Tsukamoto T, Iwasawa A, Furuya R, Sonoda T, Mori M. Ejaculatory disorders caused by alpha-1 blockers for patients with lower urinary tract symptoms suggestive of benign prostatic hyperplasia: comparison of naftopidil in a randomized multicenter study. Urol Int. 2009;83(1):49-54

32. Yokoyama T, Hara R, Fukumoto K, et al. Effects of three types of alpha-1 adrenoceptor blocker on lower urinary tract symptoms and sexual function in males with benign prostatic hyperplasia. Int $J$ Urol. 2011;18(3):225-230.

33. Yokoyama T, Kumon H, Hasu Y, Takamoto H, Watanabe T. Comparison of 25 and $75 \mathrm{mg} /$ day naftopidil for lower urinary tract symptoms associated with benign prostatic hyperplasia: a prospective, randomized controlled study. Int J Urol. 2006;13(7):932-938.

34. Kadekawa K, Sugaya K, Ashitomi K, Nishijima S. Clinical efficacy of $\alpha 1$-adrenergic receptor antagonist naftopidil $75 \mathrm{mg} /$ day in patients with benign prostatic hyperplasia. LUTS. 2010;2:106-112.

35. Tsuritani S, Nozaki T, Okumura A, Kimura H, Kazama T. A prospective, randomized, controlled, multicenter study of naftopidil for treatment of male lower urinary tract symptoms associated with benign prostatic hyperplasia: $25 \mathrm{mg}$ once daily in the evening compared to $25 \mathrm{mg}$ thrice daily. Urol Int. 2010;85(1):80-87.

36. Funahashi Y, Hattori R, Matsukawa Y, Komatsu T, Sassa N, Gotoh M. Clinical efficacy of a loading dose of naftopidil for patients with benign prostatic hyperplasia. World J Urol. 2011;29(2):225-231.

37. Oh-oka H. Usefulness of naftopidil for dysuria in benign prostatic hyperplasia and its optimal dose: comparison between 75 and $50 \mathrm{mg}$. Urol Int. 2009;82(2):136-142.

38. Oh-oka H. Effect of naftopidil on nocturia after failure of tamsulosin. Urology. 2008;72(5):1051-1055.

39. Takahashi S, Tajima A, Matsushima H, Kawamura T, Tominaga T, Kitamura T. Clinical efficacy of an alpha1 A/D-adrenoceptor blocker (naftopidil) on overactive bladder syndromes in patients with benign prostatic hyperplasia. Int J Urol. 2006;13(1):15-20.

40. Yokoyama O, Aoki Y, Tsujimura A, Takao T, Namiki M, Okuyama A. $\alpha 1$-adrenoceptor blocker naftopidil improves sleep disturbance with reduction in nocturnal urine volume. World J Urol. 2011;29(2): 233-238.

41. Kakizaki H, Tanaka H, Mitsui T, Nonomura K. Clinical efficacy of $\alpha 1$-blocker naftopidil in patients with overactive bladder associated with benign prostatic hyperplasia. LUTS. 2009;1:35-39. 
42. Athanasopoulos A, Gyftopoulos K, Giannitsas K, Fisfis J, Perimenis P, Barbalias G. Combination treatment with an alpha-blocker plus an anticholinergic for bladder outlet obstruction: a prospective, randomized, controlled study. J Urol. 2003;169(6):2253-2256.

43. Lee KS, Choo MS, Kim DY, et al. Combination treatment with propiverine hydrochloride plus doxazosin controlled release gastrointestinal therapeutic system formulation for overactive bladder and coexisting benign prostatic obstruction: a prospective, randomized, controlled multicenter study. J Urol. 2005;174(4 Pt 1):1334-1338.

44. Kaplan SA, Roehrborn CG, Rovner ES, Carlsson M, Bavendam T, Guan Z. Tolterodine and tamsulosin for treatment of men with lower urinary tract symptoms and overactive bladder: a randomized controlled trial. JAMA. 2006;296(19):2319-2328.

45. Rovner ES, Kreder K, Sussman DO, et al. Effect of tolterodine extended release with or without tamsulosin on measures of urgency and patient reported outcomes in men with lower urinary tract symptoms. J Urol. 2008;180(3):1034-1041.

46. Maruyama O, Kawachi Y, Hanzawa K, et al. Naftopidil monotherapy vs naftopidil and an anticholinergic agent combined therapy for storage symptoms associated with benign prostatic hyperplasia: a prospective randomized controlled study. Int J Urol. 2006;13(10):1280-1285.

47. Yokoyama T, Uematsu K, Watanabe T, Sasaki K, Kumon H, Nagai A. Naftopidil and propiverine hydrochloride for treatment of male lower urinary tract symptoms suggestive of benign prostatic hyperplasia and concomitant overactive bladder: a prospective randomized controlled study. Scand J Urol Nephrol. 2009;43(4):307-314.

48. Narayan P, Evans CP, Moon T. Long-term safety and efficacy of tamsulosin for the treatment of lower urinary tract symptoms associated with benign prostatic hyperplasia. J Urol. 2003;170(2 Pt 1):498-502.

49. Schulman CC, Lock TMTW, Buzelin J-M, et al. Long-term use of tamsulosin to treat lower urinary tract symptoms/benign prostatic hyperplasia. J Urol. 2001;166(4):1358-1363.

50. Masumori N, Hashimoto J, Itoh N, Tsukamoto T. Short-term efficacy and long-term compliance/treatment failure of the alpha1 blocker naftopidil for patients with lower urinary tract symptoms suggestive of benign prostatic hyperplasia. Scand J Urol Nephrol. 2007;41(5):422-429.
51. De la Rosette JJMCH, Kortmann BBM, Rossi C, Sonke GS, Floratos DL, Kiemeney. Long-term risk of re-treatment of patients using alpha-blockers for lower urinary tract symptoms. J Urol. 2002;167(4):1734-1739.

52. Kawachi Y, Sakurai T, Sugimura S, et al. Long-term treatment and prognostic factors of a1-blockers for lower urinary tract symptoms associated with benign prostatic hyperplasia: a pilot study comparing naftopidil and tamsulosin hydrochloride. Scand J Urol Nephrol. 2010; 44(1):38-45.

53. Kojima Y, Sasaki S, Shinomura H, et al. Change of expression levels of alpha 1-adrenoceptor subtypes by administration if alpha 1dadrenoceptor-subtype selective antagonist naftopidil in benign prostatic hyperplasia patients. Prostate 2007;67(12):1285-1292.

54. Hisasue S, Furuya R, Itoh N, Kobayashi K, Furuya S, Tsukamoto T. Ejaculatory disorder caused by alpha-1 adrenoceptor antagonists is not retrograde ejaculation but a loss of seminal emission. Int J Urol. 2006; 13(10):1311-1316.

55. Kirby RS, O’Leary MP, Carson C. Efficacy of extended-release doxazosin and doxazosin standard in patients with concomitant benign prostatic hyperplasia and sexual dysfunction. BJU Int. 2005;95(1): 103-109.

56. Van Moorselaar RJA, Hartung R, Emberton M, et al. Alfuzosin $10 \mathrm{mg}$ once daily improves sexual function in men with lower urinary tract symptoms and concomitant sexual dysfunction. BJU Int. 2005;95(4): 603-608.

57. Oshika T, Ohashi Y, Inamura M, et al. Incidence of intraoperative floppy iris syndrome in patients on either systemic or topical $\alpha 1$-adrenoceptor antagonist. Am J Ophthalmol. 2007;143(1):150-151.

58. Komiya A, Suzuki H, Awa Y, et al. Clinical effect of naftopidil on the quality of life of patients with lower urinary tract symptoms suggestive of benign prostatic hyperplasia: a prospective study. Int J Urol. 2010; 17(6):555-562.

59. Awa Y, Suzuki H, Hamano S, et al. Clinical effect of alpha 1D/A adrenoceptor inhibitor naftopidil on benign prostatic hyperplasia: an International Prostate Symptom Score and King's Health Questionnaire assessment. Int J Urol. 2008;15(8):709-715.
Therapeutics and Clinical Risk Management

\section{Publish your work in this journal}

Therapeutics and Clinical Risk Management is an international, peerreviewed journal of clinical therapeutics and risk management, focusing on concise rapid reporting of clinical studies in all therapeutic areas outcomes, safety, and programs for the effective, safe, and sustained use of medicines. This journal is indexed on PubMed Central, CAS,

\section{Dovepress}

EMBase, Scopus and the Elsevier Bibliographic databases. The manuscript management system is completely online and includes a very quick and fair peer-review system, which is all easy to use. Visit http://www.dovepress.com/testimonials.php to read real quotes from published authors. 